\title{
Evaluation of Enterostomal Therapist (ET) Nurses Intervention on Ostomy Visits
}

\author{
Wang Ling Yan ${ }^{1, ~ *, ~ J i a n g ~ M e n g ~ X i a o ~}{ }^{2}$, Xiao Fang ${ }^{3}$ \\ ${ }^{1}$ Department of Nursing, Cancer Center of Sun Yat-sen University, Guangzhou, China \\ ${ }^{2}$ Department of Urology, Cancer Center of Sun Yat-sen University, Guangzhou, China \\ ${ }^{3}$ Department of Gastric Surgery, Cancer Center of Sun Yat-sen University, Guangzhou, China
}

Email address:

wangly@sysucc.org.cn (Wang Ling Yan)

${ }^{*}$ Corresponding author

\section{To cite this article:}

Wang Ling Yan, Jiang Meng Xiao, Xiao Fang. Evaluation of Enterostomal Therapist (ET) Nurses Intervention on Ostomy Visits. American Journal of Nursing Science. Vol. 8, No. 6, 2019, pp. 342-345. doi: 10.11648/j.ajns.20190806.18

Received: September 19, 2019; Accepted: December 4, 2019; Published: December 9, 2019

\begin{abstract}
Objective: The aim of this study was to explore the effectiveness of interventions provided by Enterostomal Therapist (ET) Nurses to visitors of ostomates. Methods: ET Nurses carried out intervention methods of selection, training, organization of visiting group during enterostomy visiting works, this study summarized and analyzed the influence of various intervention methods on the growth of enterostomy visitor numbers and the work of ostomate visits. Results: The intervention program of ostomate visitors adopted by our hospital could effectively promote the growth of ostomate visitor numbers, facilitate the smooth progress of enterostomy visits, lighten the psychological burden of patients and their families in clinical application. Conclusion: The ostomate visits' intervention program constructed by ET nurses in our hospital was scientific and feasible. Through strict screening, scientific training, reasonable scheduling, continuous exchange and learning and hospital support, we have created an excellent team which provides high-quality visiting service for patients with enterostomy during perioperative period.
\end{abstract}

Keywords: Enterostomy, Enterostomal Therapist, Ostomate, Ostomy Visits, Evaluation

\section{Introduction}

Participants of the ostomate visitors program in our region are made up of members who have had ostomy surgery and have been living with an ostomy for several years. They have good experience in in providing self-care of their stoma. They have high ideological levels and are always willing to help other patients with stomas adjust to living with a stoma. In countries and regions where Ostomy Organizations or ET Nurses are more active, the voluntary service programs of ostomy visitors providing pre and post-operative hospital visits to people who may have or have had a stoma has been in place for nearly 30 years. The guidance and support provided by ostomy visitors has reportedly been of great help to new ostomy patients [1].

As early as 1998, the ET nurse in our hospital began to organize ostomy visitors to help with the perioperative counselling of prospective ostomy patients. An effective intervention scheme for potential ostomy visitors has been constructed and good results have been obtained. The details of ostomy visits are reported as follows:

\subsection{Managing Selection of Ostomy Visitors}

After being recommended by doctors, other ET nurses and ostomy patients, the ET Nurse initially contacted those colostomy patients recommended to be ostomy visitors to communicate and inform them of the purpose and significance of being an ostomy visitor. Ostomy visitors were finally selected according to their physical condition,, adjustment to and self-care ability of their ostomy, and other factors such as communication skills and family support. Moreover, during their daily work, if any ET nurses found an ostomate who had the potential to be a good Ostomy Visitor, the ET nurses would discuss the role and function of the ostmy visitor with them and try to encourage those people with the right skills to join the Ostomy Visitor Program. In this way, the team could be expanded gradually. 


\subsection{Training of Visitors}

Before visiting and counselling patents with stomas, the new ostomy visitors participated in 4 to 6 training sessions provided by the ET nurses. Referring to the training course guidelines of International Ostomy Association (IOA), the ET nurses modified the curriculum appropriately according to the characteristics of the local population in this area. The contents of the training program included anatomical and physiological knowledge of colostomy related surgery; basic knowledge of colostomy care, communication skills to be used during visits and, basic etiquette, rules and regulations for ostomy visitors and their responsibilities as an Ostomy Visitor.

\subsection{Role of Ostomy Visitors}

Except for the National holidays Ostomy visits are required to be carried out 1 to 2 times a week by Ostomate Visitors. During each visit, two visitors were arranged for bedside communication with patients who were about to undergo or had undergone ostomy surgery on rehabilitation proceses and adapting to life and returning to society after ostomy surgery. Visitors were encouraged to listen to the concerns of the patients during these visits, use their own experiences to comfort patients, and enhance their confidence in active treatment and to re-establish their own healthy body image.

If the visitors agreed, their contact information was given to the patients, because this could facilitate further contact after discharge from hospital.

\subsection{Evaluation of Ostomy Visitor Program}

If the visitors agreed, their contact information were allowed to be given to the patients, because this can facilitate further contact after discharge from hospital.

In order to evaluate the effectiveness of the Ostomy Visitor Program a three phased evaluation method was developed, which involved categorizing ostomy visitors by experience e.g. those with $\leq 1$ year or those with $\geq 2$ years of experience. Quarterly group meetings were established for all Ostomy visitors.

For those Ostomy Visitors who had less than 1 years experience, ET nurses would follow the visit, evaluate the effect of the visit, communicate with the visitors on the problems existing during the visit, and give advice or take measures to help them improve (what advice would be provided to help ostomy visitors improve?). For Ostomy visitors who had been engaged in visitations for more than 1 years, the ET nurses would just participate randomly instead of following up the visit every time. All visitors gathered quarterly to summarize the problems in the process of the visits and seek solutions to any problems identified. During these conferences, we find deficiencies and improve continuously (please provide an example fo deficiencies found and what you did to correct these deficiencies).

\subsection{Hospital Support for Visitors and Their Association}

ET Nurses in our centre communicated with hospital leaders actively and obtained the support of hospital leaders to issue official documents for each Ostomy Visitor. This legalized their role and facilitated their access to the hospital. An Ostomy Visitors association was set up, and competent visitors were arranged to form a council and take up other important positions of the association, so as to promote the overall development of the organization. ET nurses helped to arrange the principal heads in the association to attend the international meetings and promote communication between Ostomy vistors in different regions. Our hospital reimbursed each Ostomy visitor a small amount for transportation expenses for each visit made by the visitors. Leaders of the Ostomy Visitors Association kept the fund of the team and used it to fund the activities on the basis of soliciting every member's opinion.

\subsection{Magazines, Newspapers and Books for Ostomy People}

ET nurses in our hospital assisted in establishing a Magazine of Guangzhou Stoma Association. There is also a Cancer Prevention Newspaper, which is published quarterly. We often encourage ostomy visitors to share their experiences as a visitor and ostomy self-care in the Guangzhou Stoma Association magazine and Cancer Prevention Newspaper. Our doctors and ET nurses often share their stoma care experiences and useful health knowledge in the magazine and newpaper. By these means, we attracted more people's interest and desire in participating in the Ostomy Visitors Program and helping most patients re-gain a sense of belonging.

In addition to the magazine and newspaper, we wrote books for ostomoy patients. These books were aimed at disseminating knowledge of ostomy surgery and rehabilitation and enhancing the confidence of patients to overcome the underlying disease. It also explained the role and function of ET Nurses now and into the future.

\section{Results}

Twenty eight Ostomy Visitors were enrolled for the study between May 1998 and May 2018 from Sun Yat-sen University Cancer Center through screening. Education levels of visitors were as follows: 22 of them are above undergraduate, and 6 are below undergraduate. Career status was as follows: 13 on-the-job visitors, 8 educators, and 15 retired people, 12 of whom have ever served as middle or senior management staff. The visitors' age ranged from 42 to 73 years old. The average age was 57 years old. There were 17 males and 11 females. All Ostomy Visitors included in the study $\mathrm{T}$ were evaluated comprehensively by ET nurses. They all had an optimistic attitude towards life, had good communication and organization abilities, plenty of free time and high degree of family support. They were also compassionate and willing to help others.

With the active assistance of ET Nurses, our hospital has supported our Ostomy visiting service for 20 years. The total number of patients who have benefited from the Ostomy visiting service is more than 6000 during 20 years. Through these visits, the psychological problems of many ostomy 
patients during the perioperative period have been alleviated. Our hospital's ET Nurses have assisted ostomy volunteers to establish and become members of an ostomy volunteer association. Competent visitor hold the post of the chairman of the association. Over the years, the ostomy volunteer association has actively participated in domestic and international ostomy exchanges and helped organize ostomy activities on various major festivals such World Ostomy Day® They also wrote a manuscript of their personal experience which was published in Magazine, Newspaper or Books. It can be said that through scientific and effective management, our center has successfully set up an effective enterostomy volunteer team.

\section{Discussion}

Research has shown that Ostomy visitors can influence patients' psychology and self care ability by sharing their own experiences and presenting a good healthy image [2-4]. Perioperatively for patients about to have a olostomy, doctors, nurses, and others' words are not as convincing as those of an Ostomy visitor. Only when patients see with there own eyes that people with an ostomy can lead happy lives after the same surgey can they believe that the ostomy surgey is not so very horrible [5]. Communication is a founding principle of nursing and is essential in order to give patient centered care which is safe and effective. Communication skills, specifically empathy, are critical in the provision of patient-centered care [6]. Although doctors and nurses seek to use empathy to communicate with new ostomy patients in various ways, it is not always effective. It is well understood it is easier for people who have had the same experience to communicate with each other at this level [7]. Ostomy Visitors are therefore conducive to the psychological rehabilitation of patients with stomas. Patients with stomas can often relate to and more effectively communicate any difficulties they may be experiencing to the Ostomy Visitor.

ET Nurses play a very important role in building cohesive ostomy visiting teams, ET Nurses are involved in selecting and training Ostomy Visitors, communicating and coordinating ostomy visits with hospitals and evaluating the effectiveness of these visits [8]. If required ET Nurses need to intervene with the visitors professionally to ensure the right advice is provided at the right time to the right person. It is hoped these ostomy visitor groups which ET Nurses have organized help patients realize that they are not alone, they can share their feelings, thoughts and problem-solving suggestions and gain social support [9].

Hospital approval makes Ostomy visiting work a part of specialist care and ensures its legitimacy [10]. However, during the visiting period, the ET Nurse should supervise visitors to make sure that they follow the hospital's regulations, protect the privacy of patients and refrain from commercial activities [11].

For visitors, knowledge and passion are important elements that can decide whether the visitor's work can be done well or not $[12,13]$. ET Nurses need to provide training curriculum to
Ostomy visitors to assist them to acquire the necessary knowledge [14]. Just as research shows, Visitors benefit from the helping program and demonstrate a greater level of acceptance of their ostomy [15]. Special funds given by the hospital is also a key element that assists in maintaining the long-term development of the Ostomy Visitors Program [10]. Although all the visitors' household finances in our group were above the average level in our city, special funding to supporr their roles can help retain their passion and make them feel their work is valued. In our center, special funds were mostly used to finance the activities ostomy people organized, which was an incentive for the whole group and was conducive to the overall development of the project.

\section{Summary}

In conclusion, with the coordination and cooperation of ET Nurses, visitation personnel and hospital leaders, it is feasible for the Ostomy Visitors to join in perioperative nursing care of patients who are about to or have undergone ostomy surgery. As early as 20 years ago, it was reported that Ostomy Visitors were helpful for patients with ostomy in perioperative period. Our centre has probvidced an Ostomy visitor program for over 20 years and we continue to build upon this experience to improve the service provided. A great number of ostomy patients have benefited from our Ostomy Visitors. The key to our success has been the effective intervention of ET Nurses, who have promoted the development of Ostomy visiting team and ensured the safe behavior of the Ostomy Visitor.

\section{References}

[1] Rheaume A, Gooding B A. Social support, coping strategies, and long-term adaptation to ostomy among self-help group members [J]. J Enterostomal Ther, 1991, 18 (1): 11-15.

[2] Zheng L, Wan L, Yunkun L. Clinical study of colostomy visitor on improving the self-efficacy of colostomy patients [J]. Jiangxi Medical Journal, 2015.

[3] Zhu W, Wu A, Yang Q, et al. Effect of collaborative care model with peer support group on self-care and adjustment in patients with a permanent colostomy [J]. Journal of Nursing Science, 2015.

[4] Hwang J H, Yu C S. Depression and resilience in ulcerative colitis and Crohn's disease patients with ostomy [J]. Int Wound J, 2019, 16 Suppl 1: 62-70.

[5] Bulkley J E, Mcmullen C K, Grant M, et al. Ongoing ostomy self-care challenges of long-term rectal cancer survivors $[\mathrm{J}]$. Support Care Cancer, 2018, 26 (11): 3933-3939.

[6] David S, Larson M. Athletes' Perception of Athletic Trainer Empathy: How Important Is It? [J]. J Sport Rehabil, 2018, 27 (1): $8-15$.

[7] Xu S, Zhang Z, Wang A, et al. Effect of Self-efficacy Intervention on Quality of Life of Patients With Intestinal Stoma [J]. Gastroenterol Nurs, 2018, 41 (4): 341-346. 
[8] Zavotsky K E, Ciccarelli M, Pontieri-Lewis V, et al. Nursing Morbidity and Mortality: The Clinical Nurse Specialist Role in Improving Patient Outcomes [J]. Clin Nurse Spec, 2016, 30 (3): 167-171.

[9] Karabulut H K, Dinc L, Karadag A. Effects of planned group interactions on the social adaptation of individuals with an intestinal stoma: a quantitative study [J]. J Clin Nurs, 2014, 23 (19-20): 2800-2813.

[10] Berti-Hearn L, Elliott B. A Resource Guide to Improve Nursing Care and Transition to Self-Care for Patients With Ostomies [J]. Home Healthc Now, 2018, 36 (1): 43-49.

[11] Maydick-Youngberg D. A Descriptive Study to Explore the Effect of Peristomal Skin Complications on Quality of Life of Adults With a Permanent Ostomy [J]. Ostomy Wound Manage, 2017, 63 (5): 10-23.
[12] Ferreira E D, Barbosa M H, Sonobe H M, et al. Self-esteem and health-related quality of life in ostomized patients [J]. Rev Bras Enferm, 2017, 70 (2): 271-278.

[13] Sarabi N, Navipour H, Mohammadi E. Relative Tranquility in Ostomy Patients' Social Life: A Qualitative Content Analysis [J]. World J Surg, 2017, 41 (8): 2136-2142.

[14] Steinhagen E, Colwell J, Cannon L M. Intestinal Stomas-Postoperative Stoma Care and Peristomal Skin Complications [J]. Clin Colon Rectal Surg, 2017, 30 (3): 184-192.

[15] Trainor M A. Acceptance of ostomy and the visitor role in a self-help group for ostomy patients [J]. Nurs Res, 1982, 31 (2): 102-106. 